\title{
Long-term follow-up of choroidal neovascularization secondary to angioid streaks: case series and literature review
}

This article was published in the following Dove Press journal:

Clinical Ophthalmology

4 July 2012

Number of times this article has been viewed

\section{Saba Al-Rashaed \\ J Fernando Arevalo}

King Khaled Eye Specialist Hospital, Riyadh, Saudi Arabia
Correspondence: Saba Al-Rashaed King Khaled Eye Specialist Hospital, PO Box 7I9I, Riyadh II462, Saudi Arabia Tel +966 I482 I234

Fax +966 I482 I234, extension 1908

Email srashaed@kkesh.med.sa
Background: The purpose of this paper is to report the clinical course of choroidal neovascularization (CNV) secondary to angioid streaks and the outcomes in response to different treatment modalities.

Methods: This was a case series of two consecutive patients (four eyes) with CNV secondary to angioid streaks. Visual acuity, ophthalmological examination, color photographs, fluorescein angiography, and optical coherence tomography were used to assess the outcomes of treatment.

Results: Two eyes were treated with photodynamic therapy for subfoveal choroidal neovascular membrane, one eye underwent thermal laser photocoagulation for extrafoveal CNV followed by intravitreal bevacizumab for subfoveal $\mathrm{CNV}$, and one eye underwent intravitreal bevacizumab for subfoveal CNV. The follow-up period was 4-6 years. The final visual acuities of all eyes were $20 / 300$ or worse with large submacular fibrosis.

Conclusion: CNV secondary to angioid streaks in these two patients had a poor prognosis despite undergoing different types of treatment. Poor outcome was likely related to frequent recurrence and newly developed CNV, which remained a clinical concern in these cases.

Keywords: choroidal neovascular membrane, angioid streaks, intravitreal bevacizumab, photodynamic therapy

\section{Background}

Angioid streaks are jagged, tapering linear breaks in Bruch's membrane that typically radiate from the peripapillary region. ${ }^{1,2}$ Angioid streaks are due to pathological changes in Bruch's membrane, which were confirmed histologically in the late 1930s. In some diseases, including pseudoxanthoma elasticum, Ehlers-Danlos syndrome, Paget's disease, and various blood dyscrasias, such as sickle cell disease, Bruch's membrane may become calcified and brittle with subsequent development of cracks. ${ }^{2-4} \mathrm{New}$ blood vessels may proliferate in the cracks, generating choroidal neovascularization (CNV), with subsequent serous and hemorrhagic detachment of the fovea (the most serious complication), choroidal rupture, or foveal involvement by a streak with damage to the retinal pigment epithelium and choriocapillaris. ${ }^{46} \mathrm{CNV}$ is the major cause of severe visual loss in these patients. ${ }^{4-11}$ Several strategies have been proposed to control CNV secondary to angioid streaks, including argon laser photocoagulation, transpupillary thermotherapy, photodynamic therapy, surgical removal, and intravitreal bevacizumab or ranibizumab injections. ${ }^{12-18}$ However, the major conundrum in managing this disease entity is recurrence and new development of choroidal neovascular membrane. In this case series, we present the long-term responses and outcomes in 
four eyes of two patients with CNV-related angioid streaks that underwent different modalities of treatment. In addition, we have undertaken a literature review of angioid streaks secondary to $\mathrm{CNV}$.

\section{Case report I}

A 56-year-old male patient presented with a history of gradual loss of vision over 6 months in the right eye. He received photodynamic therapy elsewhere 2 months prior to presentation. Visual acuity was 20/160 OD and 20/40 OS. Dilated fundus examination showed partially active subfoveal CNV with active subretinal hemorrhage and subretinal fluid, which was connected to the area of angioid streaks. The fundus findings were confirmed by intravenous fluorescein angiography and optical coherence tomography which showed classical subfoveal CNV that leaked at the end of the study, there was evidence of angioid streaks emanating from the optic disc with evidence of peau d'orange appearance at the posterior pole of the fundus in both eyes (Figure 1A). The patient was treated with an intravitreal injection of triamcinolone acetonide $4 \mathrm{mg} / 0.1 \mathrm{~mL}$ followed by photodynamic therapy. Three months later, CNV resolved. However, at 3 months, the patient developed a large fibrotic membrane with a concurrent drop in vision to 20/300 (Figure 1B).

Two years later the patient presented with a history of metamorphopsia OS 3 days prior to presentation. His visual acuity was 20/60 OS, dilated fundus examination showed active juxtafoveal CNV emanating from the angioid streaks with subretinal hemorrhage and subretinal fluid which was confirmed by intravenous fluorescein angiography that demonstrated classical juxtafoveal CNV with active leaking.

The patient underwent monthly injections of bevacizumab $1.25 / 0.05 \mathrm{~mL}$ for 3 months. Subsequent clinical evaluation indicated stable vision and no leakage from CNV, confirmed by intravenous fluorescein angiography and optical coherence tomography (Figure 1C). Six months later, he presented with a drop in vision OS to 20/160 with evidence of active subfoveal CNV emanating from the previous CNV. The patient received the same regimen of intravitreal bevacizumab for 3 months (Figure 1D). The CNV was quiescent at 4 years follow-up (last visit to date), and his vision was $20 / 300$ in both eyes secondary to a large fibrotic macular scar (Figure 1E).

\section{Case report 2}

A 41-year-old female presented with a history of metamorphopsia of 3 months' duration. Visual acuity was 20/20 OD and 20/125 OS. Dilated fundus examination showed active subfoveal CNV with subretinal hemorrhage and subretinal fluid confirmed by intravenous fluorescein angiography that demonstrated classical subfoveal CNV with active leakage. In addition, there was evidence of angioid streaks emanating from the optic disc with evidence of peau d'orange fundus in both eyes (Figure 2A). Examination of the neck and axilla showed coalesced yellow papules and thickening of the skin with a peau d'orange appearance suggestive of pseudoxanthoma elasticum. The patient underwent photodynamic therapy with a poor response at 2 months, which warranted a second photodynamic therapy session. Five months later, active subfoveal CNV OS was still present, and a new extrafoveal CNV emanating from the angioid streaks was demonstrated OD by intravenous fluorescein angiography, which showed classic $\mathrm{CNV}$ with active leakage. At this point, the patient underwent laser photocoagulation OD and photodynamic therapy OS. Three months after treatment, CNV was quiescent in both eyes and vision was 20/20 OD and 20/200 OS. On follow-up, we noticed enlargement of the laser scar in the OD with further deterioration in vision to 20/100 without active CNV. However, $\mathrm{CNV}$ in OS showed reactivation, which prompted monthly intravitreal injection of bevacizumab $1.25 \mathrm{mg} / 0.05 \mathrm{~mL}$ for 3 months (Figure 2B). After treatment, the choroidal neovascular membrane was quiescent and vision was 20/300.

Eighteen months later, the patient presented with further loss of vision in the right eye. Vision was 20/160 and, clinically, the choroidal neovascular membrane was large and more active, incorporating the central macula (Figure 2C). The patient underwent monthly intravitreal injections of bevacizumab $1.25 \mathrm{mg} / 0.05 \mathrm{~mL}$ for 3 months; clinically the CNV was dry, confirmed by intravenous fluorescein angiography and optical coherence tomography. The last follow-up for this patient was after 6 years and her vision in both eyes was 20/300 secondary to extensive submacular fibrosis (Figure 2D and E).

\section{Discussion}

CNV represents a major cause of severe visual loss in patients with angioid streaks. CNV secondary to angioid streaks occurs in $42 \%-86 \%$ of cases, with most resulting in macular involvement and central visual loss progressing to legal blindness by 50 years of age..$^{4-11}$ The major problem in managing CNV in eyes with angioid streaks is recurrence. The majority of published studies have shown that untreated eyes with CNV have poor visual outcomes. ${ }^{4-6}$ Clarkson and Altman $^{5}$ followed 29 patients for 6 months and found that visual acuity decreased by two lines in 13 patients, with six eyes becoming legally blind from bilateral disciform scars. 



Figure I Case I. (A) Active subfoveal CNV membrane OS with subretinal hemorrhage connected to area of angioid streaks. Intravenous fluorescein angiography showed classic subfoveal choroidal neovascular membrane with leakage at the end of the study. (B) Healed CNV OS. (C) Active juxtafoveal CNV emanating from angioid streaks OD with subretinal hemorrhage. Lower left picture shows response to treatment. (D) Active subfoveal CNV OD emanating from the previous CNV. (E) Healed CNV OD. Abbreviation: CNV, choroidal neovascularization.

Several strategies have been proposed to manage CNV secondary to angioid streaks. Laser photocoagulation has been widely used to treat juxtafoveal and extrafoveal CNV in these patients to stop CNV and stabilize visual acuity. However, the high recurrence rate $(77 \%)^{4,6}$ and functional problems related to expansion of CNV or laser-induced scar toward the fovea precludes laser photocoagulation as the standard treatment for CNV-related angioid streaks. Case 2 in the current paper was treated with laser photocoagulation for an extrafoveal $\mathrm{CNV}$ in which the membrane healed with 

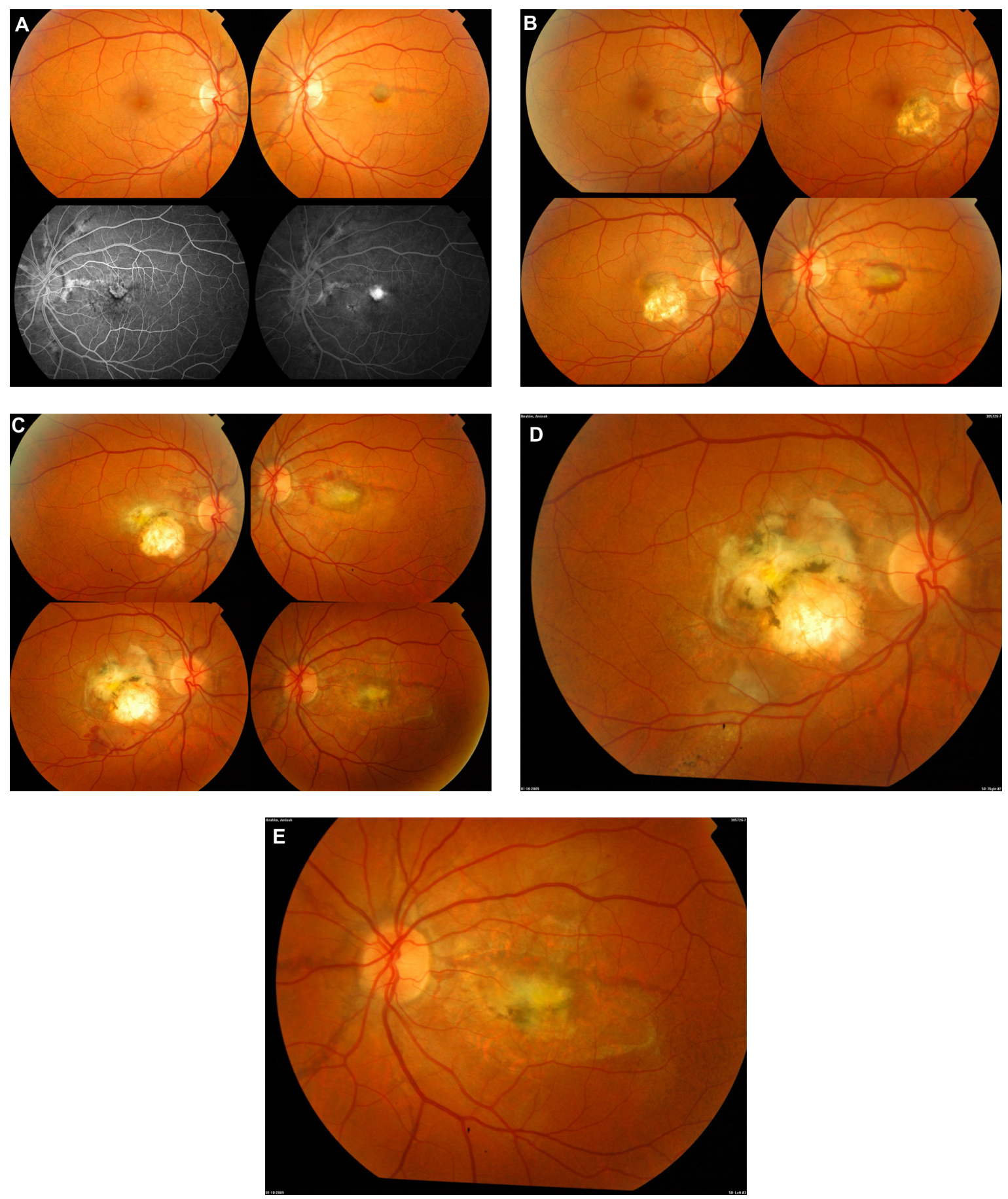

Figure 2 Case 2. (A) Active subfoveal CNV with active subretinal hemorrhage and subretinal fluid confirmed by intravenous fluorescein angiography that demonstrated classical subfoveal CNV with active leakage. In addition, there is evidence of angioid streaks emanating from the optic disc with evidence of peau d'orange fundus in both eyes. (B) Upper right active extrafoveal CNV OD. Upper left after laser treatment OD. Lower right enlargement of laser scar OD. Lower left active recurrent CNV OS. (C) Left column, new active CNV OD. Right column, active CNV OS. (D and E) Submacular fibrosis OU.

Abbreviation: CNV, choroidal neovascularization.

expansion of the scar and new development of $\mathrm{CNV}$ at the edge of the scar, which extended subfoveally.

Transpupillary thermotherapy uses a diode laser at a lower threshold that does not cause thermal burn has been used for the treatment of macular CNV of several etiologies.
Aras et a ${ }^{19}$ used transpupillary thermotherapy to treat patients with subfoveal neovascular membranes secondary to angioid streaks and concluded that it does not seem to affect the course of the disease. Aras et a ${ }^{19}$ also observed an expansion of the borders and leakage of the membrane. 
Macular translocation surgery has been reported previously ${ }^{20-22}$ which showed encouraging results, but the relevant studies are limited due to small sample size.

The results of photodynamic therapy alone also are disappointing because of the multiple treatments; the mean number of treatments ranged from 2.9 to 3.4 during a mean follow-up of at least one year. ${ }^{12-14}$ Repeated treatments with laser photocoagulation or standard fluence photodynamic therapy may cause additional ruptures in Bruch's membrane and lead to more recurrences. Menchini et $\mathrm{al}^{10}$ and Browning et al ${ }^{12}$ reported stabilization of visual acuity in a series of 34 and 23 eyes, respectively, treated with only standard fluence photodynamic therapy. However, the 2-year extension of the study by Browning et $\mathrm{al}^{13}$ showed a progressive loss of visual acuity. Shaikh et $\mathrm{al}^{9}$ and Ladas et $\mathrm{al}^{11}$ used a more aggressive treatment regimen for angioid streak-associated CNV comprising early standard fluence photodynamic therapy with retreatment at 8 -week intervals instead of the conventional 3-month intervals. Both studies ${ }^{9,11}$ concluded that early retreatment with standard fluence photodynamic therapy provided no visual benefit. Furthermore, photodynamic therapy has been associated with adverse effects on normal tissue and can cause choroidal hypoperfusion..$^{23,24}$ Hence, other treatment options, such as administration of intravitreal anti-vascular endothelial growth factor (VEGF) compounds, have been investigated. ${ }^{15-18}$

Bevacizumab (Avastin ${ }^{\circledR}$, Genetech Inc, San Francisco, $\mathrm{CA}$ ) is a recombinant humanized full-length antibody that binds to all isoforms of VEGF and has been used in an offlabel manner. The short-term efficacy of bevacizumab for angioid streaks and the fact that it will not induce direct damage to Bruch's membrane makes recurrence unavoidable over the long term. This observation has been confirmed in long-term studies with follow-up times exceeding one year, that report recurrent or newly developed CNV in different regions in half of the study cohorts. ${ }^{17,18,27}$ The use of intravitreal ranibizumab (Lucentis ${ }^{\circledR}$, Genetech Inc), the antigen-binding fragment of recombinant, humanized monoclonal antibody that neutralizes all active forms of VEGF A, was also used in CNV-related angioid streaks with promising results. ${ }^{32}$ The largest published retrospective case series investigating the use of ranibizumab in CNV secondary to angioid streaks demonstrated a stabilization of visual acuity over 24 months with a mean of 5.7 injections. ${ }^{27}$

Recently, Artunay et $\mathrm{al}^{28}$ treated 10 patients with a combination of intravitreal ranibizumab and photodynamic therapy and found a reduction or elimination of retinal edema, regression of neovascularization, and improvement or stabilization of visual acuity without any complications. The four cases with long-term follow-up in the current study failed to respond to three different modalities of treatment, and we believe this is due to the pathological nature of this disease, not the clinical management. This case report demonstrates the difficulties in management of this disease despite even anti-VEGF therapy.

In summary, despite the promising results of treatment of CNV secondary to angioid streaks using anti-VEGF compounds, recurrence and new development of CNV was an issue in these cases. This fact is demonstrated in our long-term follow-up exceeding 6 years. We believe that CNV-related angioid streaks in some cases may carry a poor prognosis, which is related to the pathological nature of this disease entity. We believe that current therapy may delay but does not eliminate progression.

\section{Disclosure}

The authors report no conflicts of interest in this work.

\section{References}

1. Connor PH, Juergens JL, Perry HO, Hollenhorst RW, Edwards JE. Pseudoxanthoma elasticum and angioid streaks: a review of 106 cases. Am J Med. 1961;30:537-543.

2. Finger RP, Charbel Issa P, Ladewig M, Holz FG, Scholl HP. Intravitreal bevacizumab for choroidal neovascularisation associated with pseudoxanthoma elasticum. Br J Ophthalmol. 2008;92:483-487.

3. Gelisken O, Hendrikse F, Deutman AF. A long-term follow-up study of laser coagulation of neovascular membranes in angioid streaks. Am J Ophthalmol. 1988;105:299-303.

4. Piro PA, Scherga D, Fine SL. Angioid streaks: natural history and visual prognosis. In: Fine SL, Owens SL, editors. Management of Retinal Vascular and Macular Disorders. Baltimore, MD: Williams \& Wilkins; 1983.

5. Clarkson JG, Altman RD. Angioid streaks. Surv Ophthalmol. 1982;116: 235-246.

6. Georgalas I, Papaconstantinou D, Koutsandrea C, et al. Angioid streaks, clinical course, complications, and current therapeutic management. Ther Clin Risk Manag. 2009;5:81-89.

7. Karacorlu M, Karacorlu S, Ozdemir H, Mat C. Photodynamic therapy with verteporfin for choroidal neovascularization in patients with angioid streaks. Am J Ophthalmol. 2002;134:360-366.

8. Sickenberg M, Schmidt-Erfurth U, Miller JW, et al. A preliminary study of photodynamic therapy using verteporfin for choroidal neovascularization in pathologic myopia, ocular histoplasmosis syndrome, angioid streaks, and idiopathic causes. Arch Ophthalmol. 2000;118: 327-336.

9. Shaikh S, Ruby AJ, Williams GA. Photodynamic therapy using verteporfin for choroidal neovascularization in angioid streaks. Arch Ophthalmol. 2003;135:1-6.

10. Menchini U, Virgili G, Introini U, et al. Outcome of choroidal neovascularization in angioid streaks after photodynamic therapy. Retina. 2004;24:763-771.

11. Ladas ID, Georgalas I, Rouvas AA, Gotsis S, Karagiannis DA, Moschos M. Photodynamic therapy with verteporfin of choroidal neovascularization secondary to angioid streaks: conventional versus early retreatment. Eur J Ophthalmol. 2005;15:69-73. 
12. Browning AC, Chung AK, Ghanchi F, et al. Verteporfin photodynamic therapy of choroidal neovascularization in angioid streaks: oneyear results of a prospective case series. Ophthalmology. 2005;112: 1227-1231.

13. Browning AC, Amoaku WM, Chung AK, et al. Photodynamic therapy for angioid streaks. Ophthalmology. 2007;114:1592.

14. Arias L, Pujol O, Rubio M, Caminal J. Long-term results of photodynamic therapy for the treatment of choroidal neovascularization secondary to angioid streaks. Graefes Arch Clin Exp Ophthalmol. 2006; 244:753-757.

15. Wiegand TW, Rogers AH, McCabe F, Reichel E, Duker JS. Intravitreal bevacizumab (Avastin) treatment of choroidal neovascularisation in patients with angioid streaks. Br J Ophthalmol. 2009;93:47-51.

16. Bhatnagar P, Freund KB, Spaide RF, et al. Intravitreal bevacizumab for the management of choroidal neovascularization in pseudoxanthoma elasticum. Retina. 2007;27:897-902.

17. Neri P, Salvolini S, Mariotti C, Mercanti L, Celani S, Giovannini A. Long-term control of choroidal neovascularisation secondary to angioid streaks treated with intravitreal bevacizumab (Avastin). $\mathrm{Br} J$ Ophthalmol. 2009;93:155-158.

18. Sawa M, Gomi F, Tsujikawa M, Sakaguchi H, Tano Y. Longterm results of intravitreal bevacizumab injection for choroidal neovascularization secondary to angioid streaks. Am J Ophthalmol. 2009;148: 584-590.

19. Aras C, Baserer T, Yolar M, et al. Two cases of choroidal neovascularization treated with transpupillary thermotherapy in angioid streaks. Retina. 2004;24:801-803.

20. Roth DB, Estafanous M, Lewis H. Macular translocation for subfoveal choroidal neovascularization in angioid streaks. Am J Ophthalmol. 2001;131:390-392.

21. Fujii GY, Humayun MS, Pieramici DJ, Schachat AP, Au Eong KG, de Juan E Jr. Initial experience of inferior limited macular translocation for subfoveal choroidal neovascularization resulting from causes other than age-related macular degeneration. Am J Ophthalmol. 2001;131:90-100.
22. Tanaka M, Shimada H, Haruyama M, Lee Z, Nakajima M, Yuzawa M. Surgical removal of choroidal neovascularization in angioid streaks. Nippon Ganka Gakkai Zasshi. 2003;107:440-444. Japanese.

23. Schmidt-Erfurth U, Schlotzer-Schrehard U, Cursiefen C, Michels S, Beckendorf A, Naumann GO. Histopathological changes following photodynamic therapy in human eyes. Arch Ophthalmol. 2002;120: 835-844.

24. Michels S, Schmidt-Erfurth U. Sequence of early vascular events after photodynamic therapy. Invest Ophthalmol Vis Sci. 2003;44:2147-2154.

25. Myung JS, Bhatnagar P, Spaide RF. Long-term outcomes of intravitreal antivascular endothelial growth factor therapy for the management of choroidal neovascularization in pseudoxanthoma elasticum. Retina. 2010;30:748-755.

26. Mimoun G, Tilleul J, Leys A, Coscas G, Soubrane G, Souied EH. Intravitreal ranibizumab for choroidal neovascularizationin angioid streaks. Am J Ophthalmol. 2010;150:692-700.

27. Kang S, Roh YJ. Intravitreal ranibizumab for choroidal neovascularisation secondary to angioid streaks. Eye. 2009;23:1750-1751.

28. Ladas ID, Kotsolis AI, Ladas DS, et al. Intravitreal ranibizumab treatment of macular choroidal neovascularization secondary to angioid streaks: one-year results of a prospective study. Retina. 2010;30:1185-1189.

29. Bloch SB, Larsen M. Fibrosis of extramacular angioid streaks following ranibizumab treatment of subfoveal choroidal neovascularization. Acta Ophthalmol. 2011;89:e102-e104.27.

30. Lazaros K, Leonidas Z. Intravitreal ranibizumab as primary treatment for neovascular membrane associated with angioid streaks. Acta Ophthalmol. 2010;88:e100-e101.

31. Mimoun G, Tilleul J, Leys A, Coscas G, Soubrane G, Souied EH. Intravitreal ranibizumab for choroidal neovascularization in angioid streaks. Am J Ophthalmol. 2010;150:692-700.

32. Artunay O, Yuzbasioglu E, Rasier R, Sengul A, Senel A, Bahcecioglu H. Combination treatment with intravitreal injection of ranibizumab and reduced fluence photodynamic therapy for choroidal neovascularization secondary to angioid streaks: preliminary clinical results of 12-month follow-up. Retina. 2011;31:1279-1286.
Clinical Ophthalmology

\section{Publish your work in this journal}

Clinical Ophthalmology is an international, peer-reviewed journal covering all subspecialties within ophthalmology. Key topics include: Optometry; Visual science; Pharmacology and drug therapy in eye diseases; Basic Sciences; Primary and Secondary eye care; Patient Safety and Quality of Care Improvements. This journal is indexed on Submit your manuscript here: http://www.dovepress.com/clinical-ophthalmology-journal

\section{Dovepress}

PubMed Central and CAS, and is the official journal of The Society of Clinical Ophthalmology (SCO). The manuscript management system is completely online and includes a very quick and fair peer-review system, which is all easy to use. Visit http://www.dovepress.com/ testimonials.php to read real quotes from published authors. 